\title{
ABORTO RETENIDO CON DEGENERACIÓN VESICULAR
}

\author{
Nicola Remy Paredes ${ }^{1}$, José Coello Limas ${ }^{1}$, Pedro Arango-Ochante ${ }^{1}$
}

\begin{abstract}
RESUMEN
Paciente mujer de 36 años de edad con amenorrea de 6 semanas, ingresa al servicio de emergencia de ginecología y obstetricia por dolor pélvico asociado a sangrado vaginal escaso y aumento de tamaño del útero para la edad gestacional, con niveles de b-HCG elevados, sospechando un embarazo molar. Se realiza Aspiración Manual Endouterina (AMEU) evidenciándose restos ovulares y vesículas perladas características de la patología en mención, sin embargo, los resultados de anatomía patológica informan muerte fetal a descartar mala perfusión materna fetal. De este caso se rescata las diferentes formas de presentación que puede presentar un aborto retenido.
\end{abstract}

Palabras clave: Aborto retenido, enfermedad trofoblástica gestacional (Fuente: DeCS BIREME)

\section{RETAINED ABORTION WITH VESICULAR DEGENERATION}

\begin{abstract}
36-year-old female patient with amenorrhea for 6 weeks, enters the emergency service of gynecology and obstetrics for pelvic pain associated with scarce vaginal bleeding and increased uterus size for the gestational age, elevated b-hcg levels and a suspected molar pregnancy. An mva is performed evidencing ovular remains and pearl vesicules characteristics of the pathology in mention, however, the results of pathological anatomy report fetal death to decart bad fetal maternal perfusion. From this case, the different forms of presentation that a retained abortion may present are rescued.
\end{abstract}

Keywords: Missed abortion, gestational trophoblastic disease. (Source: MeSH NLM).

\section{INTRODUCCIÓN}

La enfermedad trofoblástica gestacional agrupa a diferentes entidades interrelacionadas: mola completa, generalmente diploide con origen cromosómico paterno, mola parcial generalmente triploide, tumor trofoblástico del lecho placentario y coriocarcinoma, con tendencias variables a la invasión local y a las metástasis, cuyo denominador común es la hipersecreción de b-HCG. El coriocarcinoma es diploide y proviene de ambos progenitores, excluyendo probablemente su origen directo en la mola completa.

El tumor trofoblástico del lecho placentario está constituido por trofoblasto mononuclear intermedio no conteniendo vellosidades coriónicas e Inmunohistoquimicamente caracterizado por expresar muchas de sus células HPL y unas pocas HCG ${ }^{1-4}$.

La enfermedad trofoblástica gestacional es un espectro de enfermedades de la placenta, existiendo entre ellas algunas con potencial de invasión y metástasis, dentro de las cuales se incluye la mola invasiva, coriocarcinoma, tumores del sitio de inserción de la placenta y mola hidatidiforme ${ }^{5}$.

Esta última a su vez se divide en mola completa y parcial, diferenciándose en histopatología, morfología, cariotipo, malignización y comportamiento clínico.
Entre 1994 y 1995, se realizó un estudio por de Abreu y col. En el cual se analizaron histológicamente los restos ovulares de abortos incompletos en 514 pacientes, demostraron que la incidencia de enfermedad trofoblástica gestacional de $1,55 \%$, de ellas, $1,16 \%$ eran molas parciales; $57,58 \%$ aborto incompleto, 36,58 \% aborto no confirmado, $2,33 \%$ otras patologías ${ }^{1}$.

\section{CASO CLÍNICO}

Paciente mujer de 36 años, mestiza, ama de casa, sin antecedentes quirúrgicos o patológicos de importancia con formula obstétrica G5 P2022, niega uso de método anticonceptivo, acude a emergencia por presentar sangrado vaginal, dolor y amenorrea de 6 semanas. Al examen físico se palpa útero de aproximadamente $11 \mathrm{~cm}$, orificios cervicales entreabiertos, sangrado escaso sin mal olor.

Los exámenes obtenidos el día de su ingreso son grupo sanguíneo "O" Factor RH positivo hemoglobina: $14.5 \mathrm{mg} / \mathrm{dl}$ plaquetas 192,000, beta-HCG cuantitativa $761 \mathrm{mui} / \mathrm{ml}$ TGO 22u/l TGP 22u/l, GGTP 21u/l, fosfatasa alcalina $224 \mathrm{U} / \mathrm{L}$, ecografía transvaginal útero de 135 × 68 × 62 mm cavidad ocupada con contenido de vesículas hidrogenas sugerente de mola parcial, radiografía de tórax anteroposterior con silueta cardiaca conservada, senos costodiafragmáticos libres y ambos campos pulmonares sin alteraciones.

\footnotetext{
Hospital Vitarte, servicio de ginecología y obstetricia, Lima Perú.

Citar como: Remy N, Coello J, Arango-Ochante P. Aborto retenido con degeneración vesicular.. Rev Peru Investig Matern Perinat 2020; 9(4):26-28 DOI https://doi.org/10.33421/inmp.2020216
}

Recibido: 13-11-20 Aprobado: 30-12-20 


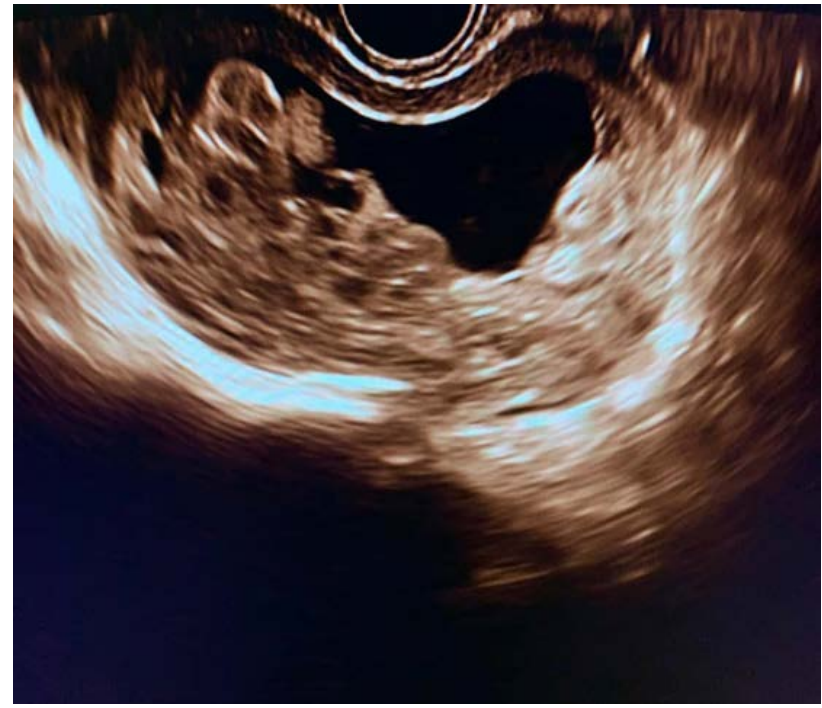

Figura 1. Ecografía donde se aprecia en cavidad uterina restos heterogéneos, algunos de aspecto quístico.

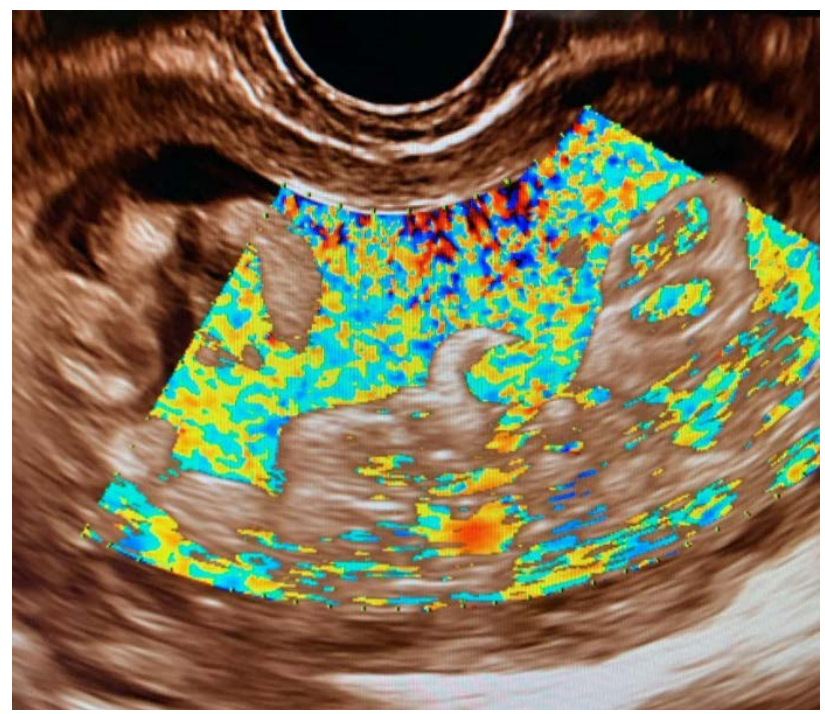

Figura 2. Ecografía donde se aprecia contenido heterogéneo sin flujo al doppler color.

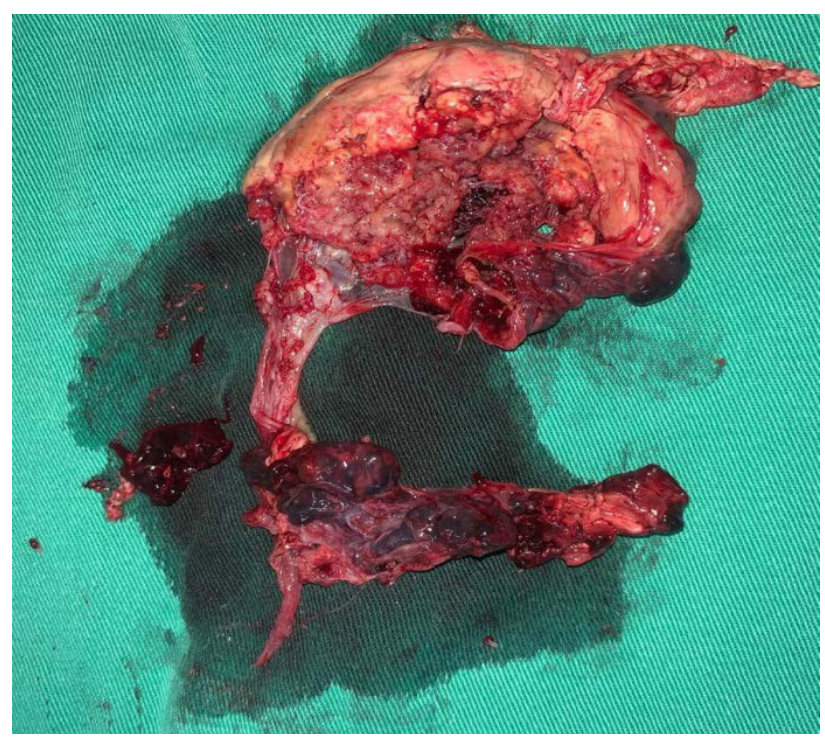

Figura 3. Vista macroscópica de restos endouterinos donde se pueden apreciar formaciones quísticas de contenido hemorrágico.
Pese a que los niveles de beta-HCG no se relacionan con los valores normalmente encontrados con una enfermedad trofoblástica gestacional, las imágenes ecográficas demostraban el diagnóstico en mención.

Al tercer día de hospitalización los niveles de b-HCG fueron $48.41 \mathrm{mui} / \mathrm{ml}$ y la ecografía muestra un endometrio de $6.4 \mathrm{~mm}$ de grosor, anexos ecográficamente normales y no se evidencia restos endouterinos.

Diagnóstico: El diagnóstico de ingreso fue descartar enfermedad trofoblástica gestacional.

Tratamiento: La paciente pasa a sala de procedimientos donde se realiza una aspiración manual endouterina evidenciándose restos endouterinos en regular cantidad y múltiples vesículas perladas de aproximadamente $5 \mathrm{~mm}$, sangrado total fue de aproximadamente $100 \mathrm{cc}$.

Evolución: Posterior al procedimiento la paciente evoluciona favorablemente sin presentar complicaciones. Negativizando la prueba de b-HCG en las semanas posteriores.

Resultados histopatológicos: Los resultados de anatomía patológica informan una placenta característica del primer trimestre con extensas áreas de infarto (>10\%), focos de calcificación, hematoma intraparenquimal, membranas fetales sin alteraciones significativas. Concluyendo hallazgos en relación a fallecimiento fetal, a descartar mala perfusión vascular materna.

\section{DISCUSIÓN}

La enfermedad trofoblástica gestacional tiene una incidencia global variable.

En estados unidos se reporta una incidencia de 121 casos por cada 100,000 embarazos; en América Latina, Brasil reporta 465 casos por cada 100,000. Entre los factores de riesgo asociados con el embarazo molar relacionados con nuestra paciente están: la edad reproductiva y el antecedente de abortos previos (riesgo aumentado por $1 \%$ ).

El diagnóstico oportuno en estos casos es decisivo para proceder con el tratamiento adecuado y prevenir una enfermedad trofoblástica gestacional persistente maligna, que ocurre incluso en $15 \%$ de los casos con embarazo molar completo y en $0.5 \%$ en casos de molas incompletas.

El misoprostol, un análogo de las prostaglandinas e1 es el fármaco más utilizado para el tratamiento médico del aborto. Su seguridad ha sido establecida por múltiples ensayos controlados y aleatorizados. Estos ensayos han excluido pacientes con infección severa o hemorragia activa.

Diferentes estudios recomiendan el uso de dilatadores mecánicos por encima del misoprostol en caso de pacientes 
con sospecha diagnóstica de enfermedad trofoblástica gestacional, reduciendo así el tiempo de evacuación y evitar complicaciones.

Es importante tener en cuenta los casos de placentación anormal, existe un riesgo de una hemorragia importante lo que desencadenará una histerectomía al momento de la evacuación uterina, principalmente en mujeres con antecedente de cesáreas previas o procedimientos evacuatorios anteriores.

En el presenta caso la paciente contaba con imágenes ultrasonográficas compatibles con embarazo molar completo, las cuales se corroboraron al momento de realizar la evacuación endouterina. Sin embargo, los resultados de anatomía patológica no confirmaron el diagnostico.

En Conclusión, la enfermedad trofoblástica gestacional si bien tiene criterios ecográficos y hallazgos macroscópicos característicos, estos no son diagnósticos, siendo necesaria el estudio anatomo patológico para confirmar el diagnóstico.

\section{Consentimiento informado}

Se explicó a la paciente el probable diagnóstico y el procedimiento a realizar. Autorizando y firmando la hoja de consentimiento informado de procedimientos quirúrgicos del hospital vitarte.

Fuentes de financiamiento: Autofinanciado.
Conflictos de interés: Los autores declaran que no tienen conflicto de intereses.

\section{REFERENCIAS BIBLIOGRÁFICAS}

1. Rodríguez H, Monsanto K, Colón JA. Enfermedad trofoblástica gestacional diagnosticada en restos ovulares obtenidos de pacientes con abortos espontáneos. Rev Obstet Ginecol Venez. 2016;76(2):76-84

2. Ovalle A, kakarieka E, Vial MT, González R, Correa A, Sukni M, Figueroa J. Histopatologia del aborto espontaneo entre 12 y 22 semanas. Rev Chil Obstet Ginecol 2003; 68(5): 361-370

3. Arellano-Borja A, Mojarra-Estrada JM, Antillón-Valenzuela J, González-Olivos A. Displasia mesenquimatosa de placenta. Hallazgos ultrasonográficos en el primer trimestre por sospecha diagnóstica precoz. Reporte de un caso y revisión de la literatura. Perinatol Reprod Hum 2011; 25 (3): 155-160

4. Ezpeleta JM, López A. Enfermedad trofoblástica gestacional aspectos clínicos y morfológicos. Rev Esp Patol. 2002;35(2): $187-200$

5. Espinoza A, Fernández R, Solar T. Actualización en patología trofoblástica gestacional: mola hidatiforme y neoplasias. Revista Médica Sinergia. 2019;4:44 -59.

6. Ponce ER, Guillén H, García AA, Ortiz ME. Embarazo ectópico ístmico-cervical con mola hidatidiforme invasora. An Med (Mex). 2016; 61 (1): 63-67.

\section{Correspondencia:}

Nicola Remy Paredes

Dirección: Calle Schipper 199 San Borja

Correo: Nicola_rp@hotmail.com

Telefono: 941934057 